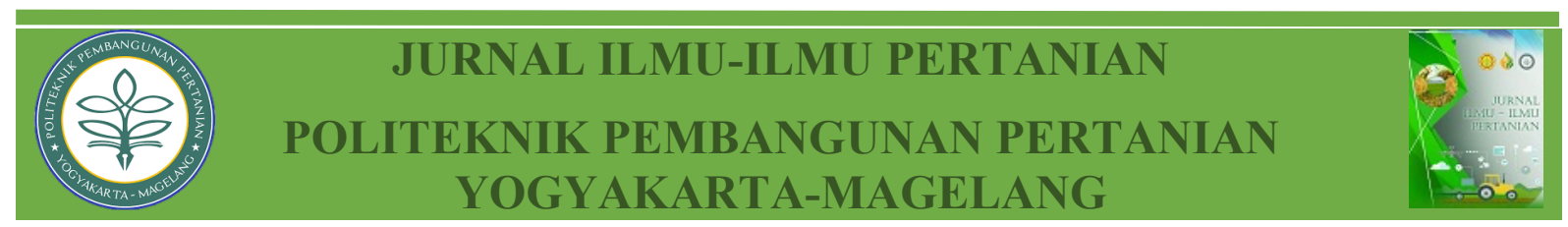

\title{
STRATEGI PENGEMBANGAN USAHA JAMUR KELOMPOK WANITA TANI (KWT) SEDYO LESTARI KALURAHAN ARGOSARI KAPANEWON SEDAYU KABUPATEN BANTUL
}

\author{
Lintang Muntias Putri ${ }^{1}$, Endah Puspitojati ${ }^{1}$, Sukadi $^{1}$ \\ ${ }^{1}$ Politeknik Pembangunan Pertanian Yogyakarta Magelang, Yogyakarta, 55167 \\ Received \\ : July $28^{\text {th }}, 2021$ \\ Accepted \\ September $8^{\text {th }}, 2021$ \\ Published \\ November $17^{\text {th }}, 2021$ \\ Copyright Notice

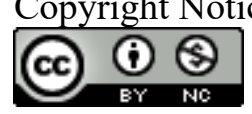

\begin{abstract}
: Authors retain copyright and grant the journal right of first publication with This work is licensed under a Creative Commons Attribution-Non Commercial 4.0 International License.
\end{abstract}

ABSTRAK: Penelitian ini bertujuan untuk mengetahui faktor internal dan eksternal Kelompok Wanita Tani (KWT) Sedyo Lestari dalam menjalankan usaha jamur serta mengetahui strategi prioritas dalam pengembangan usaha jamur. Penelitian ini dilaksanakan di Kalurahan Argosari Kapanewon Sedayu Kabupaten Bantul. Metode penelitian yang digunakan adalah metode kombinasi yang menggabungkan metode deskriptif kualitatif dan kuantitatif. Metode pengumpulan data menggunakan wawancara dan kuesioner. Kajian ini melibatkan 25 responden yang diambil secara sampling jenuh. Analisis data dilakukan dengan menggunakan SWOT. Hasil penelitian menunjukkan bahwa Faktor internal yang dianalisis dengan menggunakan matriks IFE mendapatkan total skor 2,87 dan faktor eksternal yang dianalisis dengan matriks EFE mendapatkan total skor 3,76. Berdasarkan skor IFE dan EFE diketahui pada matriks IE KWT Sedyo Lestari berada pada sel II dan pada kuadran SWOT berada pada kuadran I sehingga strategi yang perlu dilakukan adalah strategi agresif yang memanfaatkan peluang-kekuatan untuk pengembangan produk, penetrasi pasar, dan pengembangan pasar. Matriks SWOT menghasilkan 9 strategi alternatif yang selanjutnya dilakukan uji daya tarik strategi kepada responden dengan menggunakan QSPM. Strategi prioritas yang ditentukan oleh responden untuk dapat mengembangkan usaha jamur adalah strategi S-O yakni peningkatan kapasitas produksi jamur melalui peran aktif anggota KWT. Peningkatan kapasitas produksi ini dapat dilakukan dengan mengoptimalkan penggunaan dua buah oven sterilisasi, perluasan lokasi budidaya jamur, disiplin waktu budidaya, menambah target produksi, dan pencegahan hama penyakit.

Kata Kunci: usaha jamur, strategi pengembangan, SWOT.

ABSTRACT: This study aimed to determine the internal and external factors of Sedyo Lestari's Women Farmer Group (KWT) to run a mushroom business and to identify priority strategies in mushroom business development. The study was conducted in Argosari Village, Sedayu Sub District, Bantul Regency and using mix method that combined qualitative and quantitative methods. The data collection was done by interview and questionnaire methods. This study involved 25 respondents who were selected by saturated sampling. The Data analysis was 
performed using SWOT. Research shows Internal factors analyzed using the IFE matrix got a total score of 2.87, and external factors analyzed by the EFE matrix got a total score of 3.76. Based on the IFE and EFE scores, it was known that the Sedyo Lestari group put in cell II and quadrant I in the IE matrix and SWOT quadrant, respectively. Therefore, the strategy that needs to be done is an aggressive strategy that takes advantage of opportunities and strengths for product development, market penetration, and market development. The SWOT matrix resulted from 9 alternative strategies, which were then tested for the attractiveness of the strategy to respondents using QSPM. The priority strategy determined by respondents to develop a mushroom business is the $S-O$ strategy, namely increasing mushroom production capacity through the active role of KWT members. The increase of production capacity can be done by optimizing the use of two sterilizing ovens, expanding the location of mushroom cultivation, disciplining cultivation time, increasing production targets, and preventing pests and diseases.

Keywords: mushroom business, development strategy, SWOT.

\section{PENDAHULUAN}

Jamur merupakan salah satu komoditas hortikultura yang berpotensi di Indonesia. Indonesia berpotensi menjadi salah produsen penghasil jamur konsumsi karena memiliki berbagai jenis jamur yang bergizi dan dapat digunakan sebagai produk kesehatan (Pramudya \& Cahyadinata, 2012).

Daerah Istimewa Yogyakarta dalam tiga tahun terakhir, produksi jamur di Daerah Istimewa Yogyakarta mengalami fluktuasi mulai dari $369.399 \mathrm{~kg}$ pada tahun 2017 menjadi $392.416 \mathrm{~kg}$ pada tahun 2018 dan turun menjadi $296.508 \mathrm{~kg}$ pada tahun 2019 (BPS DIY, 2019). Setiap tahun permintaan jamur naik $10 \%$ khususnya jamur tiram untuk kebutuhan hotel, pencinta sayur, dan lain sebagainya (Kalsum et al., 2011). Kabupaten Bantul merupakan kabupaten yang memiliki peringkat ketiga penghasil produksi jamur terbesar di Daerah Istimewa Yogyakarta dengan jumlah produksi selama 3 tahun berturut turut sejak 2017-2019 yakni mencapai $15.609 \mathrm{~kg}, 16.851 \mathrm{~kg}$, dan 15.250 kg (BPS DIY, 2019).

Kelompok Wanita Tani (KWT) Sedyo Lestari merupakan salah satu kelompok tani yang mengembangkan usaha jamur. Berdasarkan hasil wawancara, dalam setiap bulannya kelompok wanita tani usaha jamur ini sampai tahun 2020 memiliki permintaan pasar yang cukup tinggi yakni mencapai $1.250 \mathrm{~kg}$ untuk jamur tiram, $851 \mathrm{~kg}$ jamur kuping dan 150 $\mathrm{kg}$ jamur lingzie dalam setiap bulannya. Sampai tahun 2020, Kelompok Wanita Tani Sedyo Lestari ini baru dapat memenuhi $60 \%$ dari total permintaan pasar yang cukup besar tersebut yakni baru mencapai $750 \mathrm{~kg}$ jamur tiram, $511 \mathrm{~kg}$ jamur kuping, dan $90 \mathrm{~kg}$ jamur lingzie. Rendahnya hasil produksi jamur ini disebabkan oleh beberapa hal di antaranya kurangnya ketersediaan baglog dan juga bibit jamur, terbatasnya luas lahan, dan serangan hama. Dari uraian di atas dalam rangka mengambangkan usaha jamur maka penulis akan mengkaji tentang "Strategi Pengembangan Usaha Jamur di Kelompok Wanita Tani (KWT) Sedyo Lestari Kalurahan Argosari Kapanewon Sedayu Kabupaten Bantul DIY”.

Rumusan masalah pada kajian ini adalah apa saja faktor-faktor internal (kelemahan dan kekuatan) dan apa saja faktor-faktor eksternal (peluang dan ancaman) yang ada di KWT Sedyo Lestari serta bagaimana strategi pengembangan usaha jamur KWT Sedyo Lestari?

Tujuan kajian ini adalah untuk mengetahui faktor internal (kelemahan dan kekuatan) dan faktor eksternal (peluang dan ancaman) yang ada di KWT Sedyo Lestari serta strategi pengembangan prioritas yang dapat diterapkan untuk pengembangan usaha jamur. 


\section{METODE}

Kajian ini adalah kajian dengan metode kombinasi (deskriptif kualitatif dan kuantitatif) untuk mengidentifikasi faktor internal (kekuatan dan kelemahan) dan faktor eksternal (peluang dan ancaman) dalam pengembangan usaha jamur KWT Sedyo Lestari.

Kajian ini dilakukan mulai bulan Januari-Mei 2021 di KWT Sedyo Lestari Kalurahan Argosari, Kapanewon Sedayu, Kabupaten Bantul dengan metode pemilihan lokasi dilakukan secara purposive. Responden/Sampel dalam kajian ini adalah 25 anggota KWT Sedyo Lestari yang ditetapkan dengan metode sampling jenuh.

Janis data yang digunakan dalam kajian ini adalah data primer yang bersumber dari responden dan penyuluh pertanian lapangan serta data sekunder yang berasal dari dokumen instansi terkait. Metode pengumpulan data menggunakan metode wawancara dan kuesioner.

Teknik analisis data menggunakan tahapan perumusan strategi yakni tahap pengumpulan input (input stage), tahap pencocokan (matching stage), dan pengambilan keputusan (decision stage).

\section{HASIL DAN PEMBAHASAN}

Kalurahan Argosari terletak di Kapanewon Sedayu Kabupaten Bantul Daerah Istimewa Yogyakarta di sebelah barat Kota Bantul. Jarak Kalurahan Argosari dengan Kota Bantul kurang lebih $23 \mathrm{~km}$. Kalurahan Argosari ini memiliki luas wilayah 628.472 ha dengan luas lahan sawah sebesar 179.89 ha. Kalurahan Argosari memiliki jumlah penduduk 8.650 jiwa dengan jumlah penduduk laki-laki 4.293 jiwa dan penduduk perempuan 4.312 jiwa. Kelembagaan petani di Kalurahan Argosari terdiri atas 9 kelompok tani, 4 KWT, 4 kelompok sapi potong, 1 kelompok ayam buras, 7 kelompok budidaya ikan, 2 kelompok lumbung, dan 2 kelompok agribisnis jamur.

\section{Karakteristik Responden}

Berdasarkan aspek usia anggota KWT Sedyo Lestari terbagi atas usia produktif (16-64 tahun) berjumlah 24 anggota dengan persentase $96 \%$ dan anggota KWT yang masuk kriteria tidak produktif ( $>64$ tahun) berjumlah 1 anggota dengan persentase 4 $\%$.

Berdasarkan aspek latar belakang pendidikan anggota KWT Sedyo Lestari memiliki pendidikan sangat beragam mulai dari yang tidak bersekolah sejumlah 4 anggota (16\%), tamat SD sejumlah 3 anggota $(12 \%)$, tamat SMP sejumlah 3 anggota (12\%), tamat SMA/SMK sejumlah 12 anggota (48 \%), dan tamat S1 sejumlah 3 anggota (12\%).

\section{Identifikasi Faktor Internal dan Eksternal}

Kajian strategi pengembangan dilakukan untuk mengetahui strategi prioritas yang diperlukan oleh KWT Sedyo Lestari untuk meningkatkan jumlah produksi sehingga mampu memenuhi $40 \%$ permintaan pasar. Freddy (2016) menyatakan bahwa untuk dapat merumuskan sebuah strategi usaha maka dapat dilakukan dengan perumusan analisis SWOT yang dipadukan dengan tahapan perumusan strategi.

Identifikasi faktor internal dilakukan untuk mengetahui kekuatan dan kelemahan serta faktor eksternal berupa peluang dan ancaman. Hal ini sejalan dengan pernyataan David dan David (2016) dan Pratiwi (2018) yang menyatakan bahwa unsur pengembangan usaha dapat bersumber dari dalam dan luar usaha. Pada tahap ini didapatkan 14 kekuatan antara lain dan 9 kelemahan serta 10 peluang dan 5 ancaman yang dapat dilihat pada Tabel 1 dan Tabel 2. 


\begin{tabular}{|c|c|c|}
\hline Faktor Internal & Kekuatan & Kelemahan \\
\hline Manajemen \& SDM & $\begin{array}{l}\text { 1. Anggota kelompok aktif melakukan kegiatan produksi } \\
\text { jamur } \\
\text { 2. Pengalaman anggota dalam menjalankan usaha cukup } \\
\text { lama } \\
\text { 3. Anggota kelompok aktif mengikuti kegiatan pelatihan } \\
\text { 4. Anggota kelompok berminat lebih mengembangkan } \\
\text { usaha } \\
\text { 5. Terdapat pembagian tugas dalam menjalankan usaha }\end{array}$ & $\begin{array}{l}\text { 1. Latar belakang pendidikan } \\
\text { anggota kelompok tidak } \\
\text { seimbang } \\
\text { 2. Masih kurangnya sumber daya } \\
\text { manusia untuk pemberdayaan }\end{array}$ \\
\hline Produksi & $\begin{array}{l}\text { 6. Bahan baku mudah ditemukan } \\
\text { 7. Jenis produk jamur yang dihasilkan beragam } \\
\text { 8. Tahapan produksi terstruktur }\end{array}$ & $\begin{array}{l}\text { 3. Produksi jamur belum } \\
\text { memenuhi permintaan pasar } \\
\text { 4. Keterbatasan lahan untuk } \\
\text { mengembangkan } \\
\text { produksi } \\
\text { 5. Kondisi tempat usaha masih } \\
\text { kurang luas }\end{array}$ \\
\hline Pemasaran & $\begin{array}{l}\text { 9. Harga jual jamur dapat dijangkau konsumen dan pasar } \\
\text { 10. Memiliki kemitraan dengan pihak pemasaran di luar } \\
\text { usaha } \\
\text { 11. Memiliki pelanggan tetap }\end{array}$ & $\begin{array}{l}\text { 6. Pemasaran Online mandiri } \\
\text { belum maksimal } \\
\text { 7. Tercapainya target produksi } \\
\text { masih belum stabil }\end{array}$ \\
\hline Keuangan & $\begin{array}{l}\text { 12. Melakukan pengelolaan keuangan secara rutin } \\
\text { 13. Memiliki sumber modal tetap }\end{array}$ & $\begin{array}{lll}\text { 8. } & \begin{array}{l}\text { Kendala pada bagian } \\
\text { pengelolaan keuangan }\end{array}\end{array}$ \\
\hline $\begin{array}{l}\text { Penelitian dan } \\
\text { Pengembangan }\end{array}$ & $\begin{array}{l}\text { 14. Rutin melakukan } \\
\text { pengembangan usaha untuk meningkatkan } \\
\text { produksi }\end{array}$ & $\begin{array}{l}\text { 9. Hasil penerapan penelitian dan } \\
\text { pengembangan belum } \\
\text { maksimal }\end{array}$ \\
\hline
\end{tabular}

Sumber : Olah Data Primer 2021

Tabel 2. Identifikasi Faktor Eksternal

\begin{tabular}{|c|c|c|}
\hline Faktor Eksternal & $\begin{array}{l}\text { Peluang } \\
\end{array}$ & Ancaman \\
\hline Ekonomi & $\begin{array}{l}\text { 1. Permintaan pasar jamur tinggi } \\
\text { 2. Terdapat banyak tawaran modal dari berbagai pihak }\end{array}$ & $\begin{array}{l}\text { 1. Peningkatan permintaan setiap } \\
\text { jenis produk tidak sama } \\
\text { 2. Harga jamur di pasaran banyak } \\
\text { yang dijual di luar standar }\end{array}$ \\
\hline Persaingan & $\begin{array}{l}\text { 3. Pesaing usaha jamur masih sedikit } \\
\text { 4. Pesaing banyak yang tidak memproduksi bibit sendiri }\end{array}$ & $\begin{array}{l}\text { 3. Muncul usaha jamur yang } \\
\text { mulai memperluas pasar } \\
\text { 4. Harga jual yang ditawarkan } \\
\text { usaha jamur lain lebih murah }\end{array}$ \\
\hline $\begin{array}{l}\text { Sosial, Budaya, } \\
\text { Demografi dan } \\
\text { Lingkungan }\end{array}$ & $\begin{array}{l}\text { 5. Respons masyarakat sekitar baik } \\
\text { 6. Lingkungan usaha mendukung hasil kualitas jamur }\end{array}$ & $\begin{array}{l}\text { 5. Serangan hama dan penyakit } \\
\text { secara tiba-tiba }\end{array}$ \\
\hline $\begin{array}{l}\text { Politik, Pemerintah, } \\
\text { dan Hukum }\end{array}$ & $\begin{array}{l}\text { 7. Adanya dukungan dari PPL } \\
\text { 8. Adanya dukungan dari dinas dan pemerintah berupa } \\
\text { bantuan dana dan alat }\end{array}$ & \\
\hline Teknologi & $\begin{array}{l}\text { 9. Kemudahan mengakses informasi dari internet } \\
\text { 10. Peralatan yang digunakan telah memenuhi standar }\end{array}$ & \\
\hline
\end{tabular}

Sumber : Olah Data Primer 2021

\section{Tahap Pengumpulan Input}

\section{Internal Factor Evaluation (IFE)}

Berdasarkan matriks IFE dapat diketahui bahwa kekuatan utama usaha jamur adalah anggota kelompok aktif di kegiatan produksi, jenis produk jamur beragam, harga jual jamur dapat dijangkau konsumen, serta memiliki kemitraan pemasaran dan pelanggan tetap dengan skor tertimbang 0,24 .
KWT Sedyo Lestari melakukan kegiatan produksi selama 6 kali dalam seminggu dengan jam kerja mulai pukul 08.00-16.00 WIB, di mana waktu produksi ini dapat mendukung keaktifan anggota kelompok yang semuanya masih berada dalam usia produktif. Hal ini sejalan dengan pernyataan Tjiptoherijanto (2001) tentang usia produktif mulai dari 15-64 tahun sehingga kelompok dapat 
memaksimalkan produksi produk jamur. Produk jamur di pasaran dengan harga yang dapat dijangkau oleh konsumen dan pelanggan tetap dianggap oleh anggota kelompok sebagai kekuatan karena masih dapat menghasilkan banyak produk tetapi tetap dapat laku di pasaran yang dibantu oleh mitra pemasaran. KWT Sedyo Lestari menjalin kemitraan dengan pihak pemasaran produk yang bertugas untuk memasarkan jamur kuping dan lingzie kering secara Online di luar Daerah Istimewa Yogyakarta sehingga pemasaran dapat lebih fokus dan dapat menjangkau kawasan yang lebih luas.

KWT Sedyo Lestari memiliki Kelemahan utama dalam usaha jamur antara lain latar belakang pendidikan anggota kelompok yang tidak seimbang dan kondisi tempat usaha yang masih kurang luas dengan skor tertimbang masing-masing yakni 0,02 .

Latar belakang pendidikan anggota kelompok sangat beragam mulai dari yang tidak bersekolah sampai lulusan sarjana. Keberagaman latar belakang pendidikan ini mempengaruhi proses komunikasi seharihari anggota kelompok sehingga dalam jenis kegiatan produksi tertentu sulit dipahami oleh beberapa anggota dan mengakibatkan jenis kegiatan tersebut tidak dapat dilakukan oleh semua anggota .

Selain itu, kondisi tempat usaha yang masih kurang luas juga merupakan kelemahan utama dalam usaha ini. Seperti yang diketahui bahwa permintaan jamur yang masuk ke kelompok ini selalu tinggi setiap bulannya tetapi masih belum bisa dipenuhi secara maksimal, salah satu penyebabnya adalah lokasi usaha yang memang masih kurang luas sehingga tidak mampu menampung jumlah baglog jamur yang banyak.

Faktor internal tersebut sejalan dengan pernyataan Pratiwi, (2018) yang menyatakan bahwa faktor internal yang mempengaruhi pengembangan usaha berasal dari sumber daya manusia, mitra kerja, pelanggan, dan lingkungan usaha.
Hasil input matriks IFE dapat dilihat pada Tabel 3.

\section{Eksternal Factor Evaluation (EFE)}

Berdasarkan matriks EFE dapat diketahui bahwa peluang utama antara lain permintaan pasar jamur tinggi, pesaing usaha jamur yang masih rendah, dan lingkungan usaha yang sangat mendukung kualitas jamur dengan skor tertimbang, 0,40 . Permintaan pasar yang tinggi ini datang dari berbagai daerah di Yogyakarta dan Jawa Tengah, hal ini sejalan dengan pernyataan Kalsum et al. (2011) yang menyatakan bahwa permintaan jamur khususnya jamur tiram itu selalu naik kisaran $10 \%$ per tahunnya untuk kebutuhan konsumsi. Peluang lain yang menjadi peluang utama masih sedikitnya pesaing usaha jamur serupa, seperti diketahui bahwa kebanyakan usaha jamur yang ada di Yogyakarta hanya mengembangkan satu jenis jamur. Produk jamur kelompok lain hanya seperti tiram, dengan jenis produk yang dihasilkan hanya jamur tiram saja membuat konsumen yang menginginkan jamur kuping dan lingzie akan tetap mencari ke KWT Sedyo Lestari. Beberapa pesaing usaha jamur yang berada di Kapanewon Sedayu ini seperti Pesona Jamur, dan KWT Sedyo Rahayu. Lingkungan usaha sangat mendukung hasil kualitas jamur karena untuk pengembangan budidaya jamur dilakukan dalam rumah jamur yang sudah memiliki saluran pengairan sendiri, lantai rumah yang sudah di semen bukan lagi dengan tanah yang kebersihannya terjaga sehingga membuat kualitas jamur yang dihasilkan selalu baik.

Ancaman utama antara lain peningkatan permintaan setiap produk jamur tidak seimbang dan serangan hama penyakit dengan skor tertimbang 0,08 . Permintaan setiap produk jamur tidak seimbang yang mengakibatkan kelompok tidak dapat membuat target pencapaian produksi di awal sehingga akan mengalami kebingungan saat tiba-tiba permintaan produk melambung tinggi. Serangan hama dan penyakit yang tiba-tiba menyerang 
baglgo dan juga tanaman jamur saat dibudidayakan yang mengakibatkan beberapa baglog dan jamur yang beberapa saat siap dipanen menjadi rusak dan tidak dapat dipasarkan.

Faktor eksternal dari peluang dan ancaman tersebut sejalan dengan Pratiwi
(2018) yang menyatakan bahwa faktor eksternal usaha berupa pengembangan informasi produk, pelanggan, dan lingkungan usaha. Hasil input matriks EFE dapat dilihat pada Tabel 4.

Tabel 3 Matriks IFE

\begin{tabular}{lllcc}
\hline No & Faktor Internal & Bobot & Rank & Skor \\
\hline Kekuatan & & & \\
\hline 1 & $\begin{array}{l}\text { Anggota kelompok aktif melakukan kegiatan } \\
\text { produksi jamur }\end{array}$ & 0.06 & 4 & 0.24 \\
\hline 2 & $\begin{array}{l}\text { Pengalaman anggota dalam menjalankan usaha } \\
\text { cukup lama }\end{array}$ & 0.05 & 3 & 0.15 \\
\hline 3 & Anggota kelompok aktif mengikuti pelatihan & 0.04 & 3 & 0.12 \\
\hline 4 & Anggota berminat lebih mengembangkan usaha & 0.05 & 3 & 0.15 \\
\hline 5 & Terdapat pembagian tugas produksi & 0.05 & 3 & 0.15 \\
\hline 6 & Bahan baku mudah ditemukan & 0.05 & 3 & 0.15 \\
\hline 7 & Jenis produk jamur yang dihasilkan beragam & 0.06 & 4 & 0.24 \\
\hline 8 & Tahapan produksi terstruktur & 0.05 & 3 & 0.15 \\
\hline 9 & Harga jual jamur dapat dijangkau konsumen & 0.06 & 4 & 0.24 \\
\hline 10 & Memiliki kemitraan dengan pihak pemasaran & 0.06 & 4 & 0.24 \\
\hline 11 & Memiliki pelanggan tetap & 0.06 & 4 & 0.24 \\
\hline 12 & Melakukan pengelolaan keuangan secara rutin & 0.04 & 2 & 0.08 \\
\hline 13 & Memiliki sumber modal tetap & 0.05 & 3 & 0.15 \\
\hline 14 & $\begin{array}{l}\text { Rutin melakukan kegiatan penelitian dan } \\
\text { pengembangan usaha }\end{array}$ & 0.04 & 2 & 0.08 \\
\hline Kelemahan & Latar belakang pendidikan tidak seimbang & 0.02 & 1 & 0.02 \\
\hline 1 & Masih kurangnya SDM pemberdayaan & 0.03 & 2 & 0.06 \\
\hline 2 & Produksi jamur belum memenuhi permintaan pasar & 0.04 & 2 & 0.08 \\
\hline 4 & $\begin{array}{l}\text { Keterbatasan lahan untuk mengembangkan lokasi } \\
\text { produksi }\end{array}$ & 0.03 & 2 & 0.06 \\
\hline 5 & Kondisi tempat usaha masih kurang luas & 0.02 & 1 & 0.02 \\
\hline 6 & Pemasaran Online mandiri belum maksimal & 0.04 & 2 & 0.08 \\
\hline 7 & Tercapainya target produksi masih belum stabil & 0.03 & 2 & 0.06 \\
\hline 9 & Kendala pada bagian pengelolaan keuangan & 0.05 & 2 & 0.10 \\
\hline 9 & $\begin{array}{l}\text { penerapan penelitian dan pengembangan belum } \\
\text { maksimal }\end{array}$ & 0.04 & 3 & 0.08 \\
\hline & Total & $\mathbf{1 . 0 0}$ & & $\mathbf{2 . 8 7}$ \\
\hline & & & & \\
\hline 3 & & & 2 \\
\hline
\end{tabular}

Sumber : Olah Data Primer 2021 
Tabel 4 Matriks EFE

\begin{tabular}{lllll}
\hline No & \multicolumn{1}{c}{ Faktor Eksternal } & Bobot & Rank & Skor \\
\hline Peluang & & & \\
\hline 1 & Permintaan pasar jamur tinggi & 0.10 & 4 & 0.40 \\
\hline 2 & Terdapat banyak tawaran modal dari berbagai pihak & 0.10 & 3 & 0.30 \\
\hline 3 & Pesaing usaha jamur masih sedikit & 0.10 & 4 & 0.40 \\
\hline 4 & $\begin{array}{l}\text { Pesaing banyak yang tidak memproduksi bibit } \\
\text { sendiri }\end{array}$ & 0.10 & 3 & 0.30 \\
\hline 5 & Respons masyarakat sekitar baik & 0.10 & 3 & 0.30 \\
\hline 6 & Lingkungan usaha mendukung hasil kualitas jamur & 0.10 & 4 & 0.40 \\
\hline 7 & Adanya dukungan dari PPL & 0.10 & 2 & 0.20 \\
\hline 8 & $\begin{array}{l}\text { Adanya dukungan dari dinas \& pemerintah berupa } \\
\text { bantuan dana \& alat }\end{array}$ & 0.07 & 3 & 0.21 \\
\hline 9 & Kemudahan mengakses informasi dari internet & 0.04 & 2 & 0.08 \\
\hline 10 & Peralatan yang digunakan telah memenuhi standar & 0.08 & 4 & 0.32 \\
\hline Ancaman & & & \\
\hline 1 & $\begin{array}{l}\text { Peningkatan permintaan setiap jenis produk tidak } \\
\text { sama }\end{array}$ & 0.04 & 2 & 0.08 \\
\hline 2 & $\begin{array}{l}\text { Harga jamur di pasaran banyak yang dijual di luar } \\
\text { standar }\end{array}$ & 0.06 & 3 & 0.18 \\
\hline 3 & Muncul usaha jamur yang mulai memperluas pasar & 0.06 & 3 & 0.18 \\
\hline 4 & $\begin{array}{l}\text { Harga jual yang ditawarkan usaha jamur lain lebih } \\
\text { murah }\end{array}$ & 0.07 & 3 & 0.21 \\
\hline 5 & Serangan hama dan penyakit secara tiba-tiba & 0.05 & 2 & 0.10 \\
\hline & Total & $\mathbf{1 . 0 0}$ & $\mathbf{3 . 7 6}$ \\
\hline Sul & &
\end{tabular}

Sumber : Olah Data Primer 2021

\section{Tahap Pencocokan}

Matriks IE

Berdasarkan matriks IE dapat diketahui bahwa usaha jamur KWT Sedyo Lestari berada pada divisi II sehingga perlu dilakukan strategi tumbuh dan membangun

Gambar 2 Matriks IE

yang meliputi strategi intensif (penetrasi pasar, pengembangan pasar, dan pengembangan produk) serta strategi integratif (integrasi ke depan, ke belakang, dan horizontal) (David dan David, 2016). Matriks IE dapat dilihat pada Gambar 1.

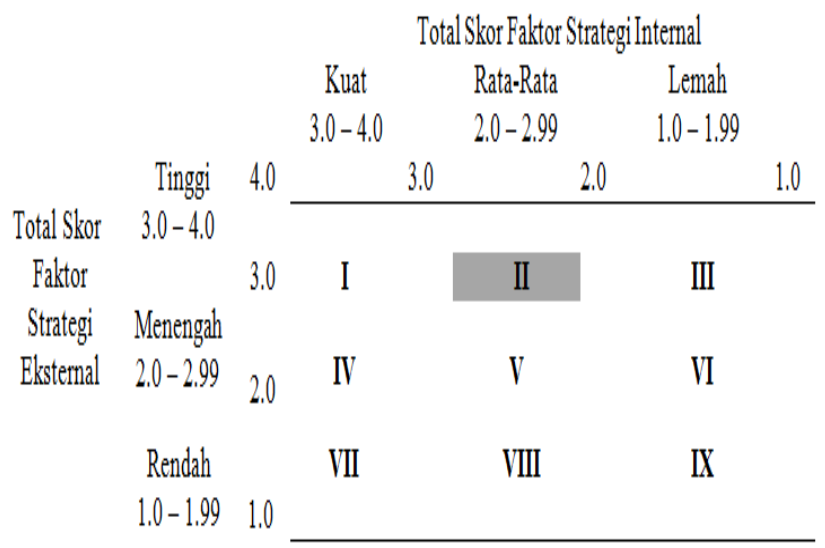

Gambar 1 Matriks IE 


\section{Matriks Kuadran SWOT}

Berdasarkan matriks kuadran SWOT dapat diketahui bahwa posisi usaha jamur KWT Sedyo Lestari berada pada kuadran I sehingga perlu dilakukan strategi agresif yang memanfaatkan kekuatan untuk memaksimalkan peluang yang meliputi strategi tumbuh dan membangun (growth oriented strategy) seperti penetrasi pasar, pengembangan pasar, dan pengembangan produk (Nofrizal dan Soviyanti, 2018). Matriks Kuadran SWOT dapat dilihat pada Gambar 2.

Berdasarkan analisis faktor internal dan eksternal diketahui bahwa tingkat produksi produk jamur masih rendah sehingga dirasa perlu mengembangkan strategi intensif pengembangan produk secara lebih agresif. Pengembangan produk dapat diartikan dengan melakukan pengembangan terhadap kualitas dan kuantitas jamur yang dihasilkan atau melakukan pengembangan terhadap kapasitas produksi jamur selama ini belum mencukupi.

Karena permasalahan utama adalah rendahnya produksi jamur, maka pengembangan produk fokus terhadap meningkatkan kapasitas produksi jamur agar bisa memenuhi permintaan pasar. Pengembangan produk yang dilakukan dapat dilakukan dengan meningkatkan kapasitas produksi jamur setiap harinya yang dari sebelumnya hanya dihasilkan dari 20.000 baglog dapat lebih ditingkatkan lagi jumlah baglog di dalam rumah jamur sehingga tingkat penjualan dapat dinaikkan. Upaya peningkatan kapasitas produksi ini adalah dengan menambah jumlah kumbung jamur yang ada dengan sentuhan teknologi yang lebih lengkap seperti pengaturan suhu ruangan, menggunakan lapisan tambahan pada dinding kumbung guna dapat mengurangi ancaman munculnya hama.

Upaya lain yang dapat dilakukan untuk meningkatkan kapasitas produksi adalah dengan menambah penggunaan

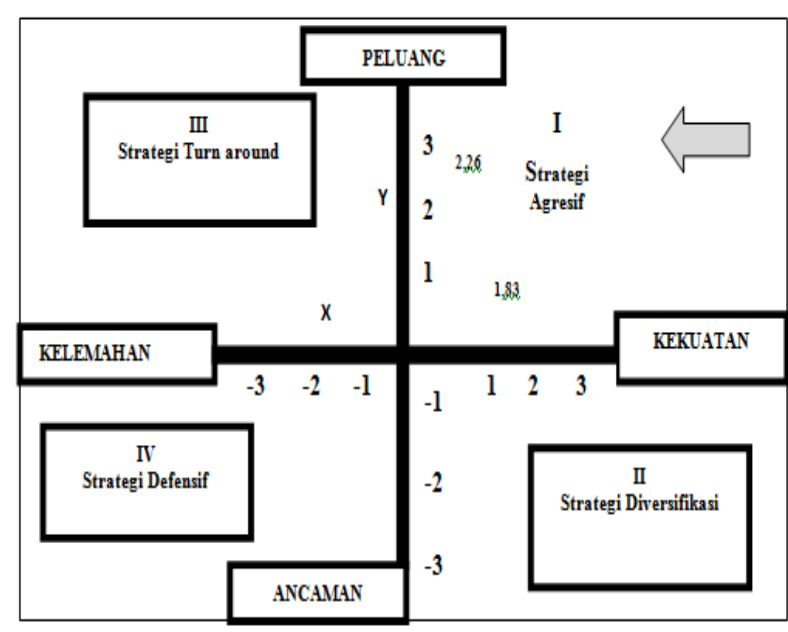

Gambar 3 Matriks Kuadran SWOT

teknologi oven sterilisasi, dan penggunaan teknologi alat penekan dalam pembuatan baglog agar jumlah baglog yang dihasilkan dapat lebih banyak sehingga jumlah jamur yang akan dihasilkan juga semakin meningkat. Strategi intensif penetrasi pasar dan pengembangan pasar dapat dilakukan dengan cara memperluas promosi dan pemasaran produk secara Online.

Strategi pengembangan produk dan penetrasi pasar yang diciptakan sejalan dengan pernyataan Made et al.(2018) yakni pengembangan produk merupakan strategi untuk meningkatkan penjualan dengan memodifikasi dan meningkatkan kualitas serta kuantitas produk sedangkan penetrasi pasar merupakan strategi untuk meningkatkan penjualan produk atas produk dan pasar yang tersedia dengan lebih agresif seperti upaya promosi dan pemasaran dengan media internet. Untuk strategi integritas ke depan dapat dilakukan dengan menjalin kerja sama dengan mitra penjualan produk untuk lebih memperluas pasar, strategi integritas ke belakang dapat dilakukan dengan menjalin kemitraan dengan pemasok bahan baku produk untuk menjaga ketersediaan bahan baku, sedangkan strategi integrative horizontal dapat dilakukan untuk memperkecil persaingan usaha dengan mempertahankan kualitas dan ciri khas produk. 


\section{Matriks SWOT}

Hasil analisa strategi pada matriks SWOT diketahui bahwa strategi alternatif yang didapatkan berjumlah 9 strategi, dengan 2 strategi S-O, 3 strategi W-O, 3 strategi S-T, dan 1 strategi W-T. Strategi ini ditentukan berdasarkan posisi usaha pada matriks IE dan Matriks Kuadran
SWOT yakni strategi yang perlu dirumuskan adalah strategi intensif meliputi penetrasi pasar, pengembangan produk, dan pengembangan pasar serta strategi integratif baik integrasi ke depan, ke belakang, maupun horizontal. Hasil perumusan strategi pada matriks SWOT dapat dilihat pada Tabel 5 .

Tabel 5 Matriks SWOT

\begin{tabular}{|c|c|c|}
\hline EFE & $\begin{array}{l}\text { Kekuatan/Strength (S) } \\
\text { 1. Anggota kelompok aktif melakukan } \\
\text { kegiatan produksi jamur } \\
\text { 2. Pengalaman anggota dalam } \\
\text { menjalankan usaha cukup lama } \\
\text { 3. Anggota kelompok aktif mengikuti } \\
\text { kegiatan pelatihan } \\
\text { 4. Anggota kelompok berminat lebih } \\
\text { mengembangkan usaha } \\
\text { 5. Terdapat pembagian tugas dalam } \\
\text { menjalankan usaha } \\
\text { 6. Bahan baku mudah ditemukan } \\
\text { 7. Jenis jamur yang dihasilkan beragam } \\
\text { 8. Tahapan produksi terstruktur } \\
\text { 9. Harga jual jamur dapat dijangkau } \\
\text { konsumen dan pasar } \\
\text { 10. Memiliki kemitraan dengan pihak } \\
\text { pemasaran di luar usaha } \\
\text { 11. Memiliki pelanggan tetap } \\
\text { 12. Melakukan pengelolaan keuangan } \\
\text { secara rutin a } \\
\text { 13. Memiliki sumber modal tetap } \\
\text { 14. Rutin melakukan kegiatan penelitian dan } \\
\text { pengembangan usaha } \\
\text { meningkatkan hasil produksi }\end{array}$ & $\begin{array}{l}\text { Kelemahan/ Weakness (W) } \\
\text { 1. Latar belakang pendidikan anggota } \\
\text { kelompok tidak seimbang } \\
\text { 2. Masih kurangnya sumber daya } \\
\text { manusia untuk pemberdayaan } \\
\text { 3. Produksi jamur belum memenuhi } \\
\text { permintaan pasar } \\
\text { 4. Keterbatasan lahan untuk } \\
\text { mengembangkan lokasi produksi } \\
\text { 5. Kondisi tempat usaha masih kurang } \\
\text { luas } \\
\text { 6. Pemasaran Online mandiri belum } \\
\text { maksimal } \\
\text { 7. Tercapainya target produksi masih } \\
\text { belum stabil } \\
\text { 8. Kendala pada bagian pengelolaan } \\
\text { keuangan } \\
\text { 9. Hasil penerapan penelitian dan } \\
\text { pengembangan belum maksimal }\end{array}$ \\
\hline $\begin{array}{l}\text { Peluang/Opportunities (O) } \\
\text { 1. Permintaan pasar jamur tinggi } \\
\text { 2. Terdapat banyak tawaran modal dari } \\
\text { berbagai pihak } \\
\text { 3. Pesaing usaha jamur masih sedikit } \\
\text { 4. Pesaing banyak yang tidak memproduksi } \\
\text { bibit sendiri } \\
\text { 5. Respons masyarakat sekitar baik } \\
\text { 6. Lingkungan usaha mendukung hasil kualitas } \\
\text { jamur } \\
\text { 7. Adanya dukungan dari PPL } \\
\text { 8. Adanya dukungan dari dinas dan pemerintah } \\
\text { berupa bantuan dana dan alat } \\
\text { 9. Kemudahan mengakses informasi dari } \\
\text { internet } \\
\text { 10. Peralatan yang digunakan telah memenuhi } \\
\text { standar }\end{array}$ & \begin{tabular}{ll}
\multicolumn{1}{c}{ Strategi S-0 } \\
1. & \multicolumn{1}{c}{ Mengoptimalkan peran anggota } \\
kelompok dalam meningkatkan \\
produksi jamur untuk memenuhi \\
permintaan pasar (S $1,2,3,4,7,14$ dan \\
O $1,2,3,6)$ \\
2. \\
Meningkatkan produksi dan penjualan \\
jamur melalui kemitraan untuk \\
mempertahankan atau meningkatkan \\
kualitas jamur ( S $6,10,11,13$ dan $\mathrm{O}$ \\
$1,2,8)$
\end{tabular} & $\begin{array}{l}\text { Strategi W-O } \\
\text { 1. Mengoptimalkan dukungan dinas } \\
\text { dan penyuluh pertanian dalam } \\
\text { pemberdayaan masyarakat sekitar } \\
\text { untuk mengembangkan usaha } \\
\text { jamur (W 2,3, 4,5,7 dan O 1,2,5,6, } \\
\text { 7,8) } \\
\text { 2. Mengoptimalkan peralatan dan } \\
\text { akses informasi untuk mencapai } \\
\text { target produksi dalam memenuhi } \\
\text { permintaan pasar (W 7,8,9 dan O } \\
\text { 1,9, 10) } \\
\text { 3. Mengoptimalkan pemasaran Online } \\
\text { ( W 6, O 9,8) }\end{array}$ \\
\hline $\begin{array}{l}\text { Ancaman/ Threats (T) } \\
\text { 1. Peningkatan permintaan setiap jenis jamur } \\
\text { tidak sama } \\
\text { 2. Harga jamur di pasaran banyak yang dijual di } \\
\text { luar standar } \\
\text { 3. Muncul usaha jamur yang mulai memperluas } \\
\text { pasar } \\
\text { 4. Harga jual yang ditawarkan usha jamur lain } \\
\text { 5. Serangan hama dan penyakit secara tiba-tiba }\end{array}$ & $\begin{array}{l}\text { Strategi S-T } \\
\text { 1. Meningkatkan promosi pada semua } \\
\text { jenis jamur melalui jaringan informasi } \\
\text { yang dimiliki mitra pemasaran ( S7, 9, } \\
\text { 10 dan T 1) } \\
\text { 2. Memfokuskan kegiatan penelitian dan } \\
\text { pelatihan untuk meningkatkan produksi } \\
\text { dan pengendalian hama penyakit (S 3, } \\
\text { 5, 13, 14 dan T 1, 5) } \\
\text { 3. Optimalisasi bahan baku untuk } \\
\text { menekan biaya produksi jamur (S 6,9 } \\
\text { dan T 2,4) }\end{array}$ & $\begin{array}{c}\text { Strategi W-T } \\
\text { 1. Meningkatkan kualitas dan ciri } \\
\text { khas produk ( W } 9 \text { dan T } 2,3,4 \text { ) }\end{array}$ \\
\hline
\end{tabular}

Sumber : Olah Data 2021 


\section{Tahap Pengambilan Keputusan}

Pengambilan keputusan dengan pengujian daya tarik 9 strategi alternatif terhadap faktor internal dan eksternaldengan menggunakan Quantitave Strategic Planning Matriks (QSPM) yang sejalan dengan tahapan pengambilan keputusan menurut David dan David (2016) yang menyatakan bahwa untuk merumuskan strategi prioritas dari beberapa strategi alternatif perlu dilakukan pengujian daya tarik faktor internal dan eksternal terhadap masing-masing strategi yang diciptakan.Dari 9 strategi alternatif yang dirumuskan, strategi yang menjadi priorotas dalam kajian ini adalah strategi I yakni mengoptimalkan peran anggota kelompok dalam meningkatkan kapasitas produksi jamur untuk memenuhi permintaan pasar.Strategi prioritas yang dipilih ini sesuai dengan anjuran strategi pada hasil penentuan posisi usaha pada matriks IE dan matriks kuadran SWOT dimana strategi ini dapat memberikan beberapa upaya yang perlu dilakukan KWT Sedyo Lestari untuk dapat meningkatkan kapasitas produksi sehingga dapat mencapai $40 \%$ permintaan pasar yang masih belum dapat dipenuhi sebelumnya. Peningkatan kapasitas produksi ini dapat dilakukan dengan cara menggunakan dua buah oven sterilisasi secara bergantian, memperluas lokasi usaha, disiplin waktu dan alur produksi, menambah target produksi, dan melakukan pencegahan hama secara serentak.Urutan prioritas strategi berdasarkan jumlah total skor daya tarik ((Total Attractive ScoreTAS) yang telah dihasilkan melalui Quantitative Strategic Planning Matriks (QSPM) dapat dilihat pada Tabel 6.

Tabel 6. Perumusan Strategi Prioritas

\begin{tabular}{clcc}
\hline No & \multicolumn{1}{c}{ Strategi Alternatif } & TAS & Peringkat \\
\hline 1 & $\begin{array}{l}\text { Mengoptimalkan peran anggota kelompok dalam meningkatkan kapasitas produksi } \\
\text { jamur untuk memenuhi permintaan pasar ( S 1,2,3,4,7, 14 dan O 1,2,3,6) }\end{array}$ & 4.86 & I \\
\hline 2 & $\begin{array}{l}\text { Meningkatkan produksi dan penjualan jamur melalui kemitraan untuk } \\
\text { mempertahankan atau meningkatkan kualitas jamur ( S 6,10,11,13 dan O 1,2 8) }\end{array}$ & 4.77 & II \\
\hline 3 & $\begin{array}{l}\text { Mengoptimalkan dukungan dinas dan penyuluh pertanian dalam melakukan } \\
\text { pemberdayaan masyarakat sekitar untuk mengembangkan usaha jamur ( W 2,3,4,5,7 } \\
\text { dan O 1,2,5,6,7,8) }\end{array}$ & 3.05 & VIII \\
\hline 4 & $\begin{array}{l}\text { Mengoptimalkan peralatan dan akses informasi untuk mencapai target produksi dalam } \\
\text { memenuhi permintaan pasar ( W 7,8,9 dan O 1,9,10) }\end{array}$ & 4.03 & III \\
\hline 5 & $\begin{array}{l}\text { Mengoptimalkan pemasaran Online ( W 6 dan O 8,9) } \\
\text { Meningkatkan promosi pada semua jenis jamur melalui jaringan informasi yang } \\
\text { dimiliki mitra pemasaran ( S 7, 9, 10 dan T 1) }\end{array}$ & 3.14 & VII \\
\hline 7 & $\begin{array}{l}\text { Memfokuskan kegiatan penelitian dan pelatihan untuk meningkatkan produksi dan } \\
\text { pengendalian hama penyakit ( S 3, 5, 13, 14 dan T 1,5) }\end{array}$ & 2.97 & VI \\
\hline 8 & Optimalisasi bahan baku untuk menekan biaya produksi jamur ( S 6,9 dan T 2, 4) & 3.24 & V \\
\hline 9 & $\begin{array}{l}\text { Meningkatkan kualitas dan ciri khas produk ( W 9 dan O 2,3,4) } \\
\text { IV }\end{array}$
\end{tabular}

Sumber : Olah Data Primer 2021

\section{SIMPULAN DAN SARAN}

Berdasarkan tujuan dan hasil kajian maka dapat disimpulkan bahwa faktor internal dalam pengembangan usaha jamur KWT Sedyo Lestari terdiri dari 14 kekuatan dengan kekuatan utama ini anggota kelompok aktif melakukan kegiatan produksi, jenis produk jamur yang dihasilkan beragam, harga jual jamur dapat dijangkau konsumen, serta memiliki kemitraan pemasaran dan pelanggan tetap dan 9 kelemahan dengan kelemahan utama dalam kelompok adalah latar belakang pendidikan anggota kelompok yang tidak seimbang dan kondisi tempat usaha yang masih kurang luas. 
Faktor eksternal dalam pengembangan usaha jamur KWT Sedyo Lestari terdiri dari 10 peluang dengan peluang utama permintaan pasar jamur tinggi, pesaing usaha jamur yang masih rendah, dan lingkungan usaha yang sangat mendukung kualitas jamur dan 5 ancaman dengan ancaman utama adalah peningkatan permintaan setiap produk jamur tidak seimbang dan serangan hama serta penyakit.

Strategi pengembangan usaha jamur prioritas yang dipilih dari 9 strategi pengembangan usaha alternatif adalah mengoptimalkan peran anggota kelompok dalam meningkatkan kapasitas produksi jamur untuk memenuhi permintaan pasar dengan menggunakan oven sterilisasi,

\section{PUSTAKA ACUAN}

BPS DIY. (2019). Statistik Hortikultura Daerah Istimewa Yogyakarta. Badan Pusat Statistik Daerah Istimewa Yogyakarta.

https://ejournal.poltektegal.ac.id/inde x.php/siklus/article/view/298http://rep ositorio.unan.edu.ni/2986/1/5624.pdf http://dx.doi.org/10.1016/j.jana.2015. 10.005http://www.biomedcentral.com $/ 1471$ -

2458/12/58http://ovidsp.ovid.com/ovi dweb.cgi?T=JS\&P. Diakses pada tanggal 30 November 2020.

David dan David. (2016). Manajemen Strategik. Jakarta: Salemba Empat.

Freddy, R. (2016). Teknik Membedah Kasus Bisnis Analisis SWOT. Jakarta: Gramedia Pustaka Utama.

Kalsum, U., Fatimah, S., \& Catur, W. (2011). Efektivitas Pemberian Air Leri Terhadap Pertumbuhan dan Hasil Jamur Tiram Putih (Pleurotus ostreatus). Jurnal Agrovigor, Vol.4(No.2), 86-92.

Made, N., Erawati, Y., Suamba, K., Wayan, N., \& Astiti, S. (2018).Strategi Pengembangan Usaha Pupuk Organik Pada UD Darma Puri Farm Di Desa Tangkas, Kecamatan Klungkung, perluasan lokasi budidaya, meningkatkan target dan disiplin waktu kerja, serta pencegahan hama penyakit.

Saran yang dapat diberikan dari hasil kajian ini adalah KWT Sedyo Lestari perlu menerapkan rekomendasi strategi pengembangan usaha jamur dengan meningkatkan kapasitas produksi jamur untuk dapat memenuhi permintaan pasar yang baru bisa dicapai sebesar $60 \%$ serta perlu adanya dukungan untuk anggota KWT Sedyo Lestari dari berbagai pihak seperti penyuluh pertanian setempat dan pemerintah agar dalam upaya peningkatan kapasitas produksi dapat berkelanjutan sehingga tujuan untuk dapat memenuhi permintaan pasar jamur dapat tercapai.

Kabupaten Klungkung. Jurnal Manajemen Agribisnis, Vol.6(2), 6982.

Nofrizal dan Soviyanti, E. (2018). Analisis Swot Untuk Menentukan Posisi Strategis Pada Universitas Lancang Kuning Pekanbaru. Jurnal Human Falah, Vol. 5(No 1), 97-116.

Pramudya, F. N., \& Cahyadinata, I. (2012). Analisis Usaha Budidaya Jamur Tiram Putih (Pleurotus ostreatus) Di Kecamatan Curup Tengah Kabupaten Rejang Lebong. Jurnal AGRISEP, 11(2), 237-250.

Pratiwi, R. (2018). Strategi Pengembangan Usaha Rengginang Pulut dengan Metode Analisis SWOT (Studi Kasus Usaha Rengginang Pulut CV. Uul Jaya Di Desa Kebun Lada Kecamatan Hinai Kabupaten Langkat). Skripsi. Tidak Diterbitkan. Fakultas Ekonomi dan Bisnis Islam. Universitas Negeri Islam: Sumatera Utara.

Tjiptoherijanto, P. (2001). Tenaga Kerja , dan Peran Serikat Pekerja dalam Peningkatan Kesejahteraan. 1-10. Majalah Perencanaan Pembangunan. Edisi 23 tahun 2001. 